\title{
La fenomenología existencial de M. Merleau-Ponty y la sociología
}

\author{
Ma Carmen López Sáenz \\ Universidad de La Rioja
}

\section{Resumen}

El artículo expone la visión de Merleau-Ponty sobre la sociedad, clarificando los fundamentos intersubjetivos de la misma, así como la influencia de este filósofo en la sociologia contemporánea al tratar temas de tecutrente actualidad como las relaciones yo-otros y sus consecuencias (empatía, amor, etc.)

Palabras clave: Merleau-Ponty, intersubjetividad, alteridad, fenomenología.

\section{Abstract. The Merleau-Ponty's existential phenomenology ant the sociology}

The article present Merleau-Ponty vision of society and the intersubjectivity foundation of modern societies. It also deals with the influence of this philosopher in contemporary sociology as fas as the self-alter relationships are concerned.

Key words: Merleau-Ponty, intersubjectivity, alterity, phenomenology.

\section{Sumario}

1. La distancia de la fenomenología husserliana

2. El yo y el otro como comportamientos

3. Crítica de la teotía sartreana

del alter ego
4. La Carne: intersubjetividad como fenómeno originario

5. La relación entre filosofia y sociología

M. Merleau-Ponty (1908-1961) fue uno de los seguidores de Husserl que quiso compaginar la fenomenología con el existencialismo con objeto de superar el idealismo y el solipsismo. Aplicó la fenomenología al estudio de la existencia humana, tanto individual como social. No entendió la fenomenología como una descripción neutra, como una simple percepción de lo inmediato, sino como una descripción que juzga y valora la realidad. Por eso su filosofía no puede equipararse con el positivismo, sino que pasa por la crítica de la metafísica tradicional (del espiritualismo y del materialismo), del racionalismo abstracto, del irracionalismo, etc. 
En el presente trabajo nos ocuparemos de su visión de la sociedad y, en concreto, de su clarificación de los fundamentos de esta última. Su interés por el hombre y por su dimensión colectiva bien merecen un lugar en la teoría sociológica contemporánea. Así lo han reconocido algunos pensadores actuales, como Schütz, Berger y Luckmann, los etnometodólogos, etc., que se han inspirado en él para desarrollar sus teorías y superar las limitaciones a las que conducen los reduccionismos.

La fenomenología aporta ricas reflexiones a la sociología. Nosotros queremos resaltar el tratamiento que aquélla realiza de la intersubjetividad. La tesis husserliana en sociología es que la sociedad está formada por sujetos y no por objetos y que, para comprender la sociedad, no hay que recurrir a entidades distintas de la interrelación entre egos. Así es como los fenomenólogos responden a Hegel. El paralelismo con Weber es evidente: la sociología comprensiva es la única capaz de dar cuenta del sentido de las acciones sociales y éstas no sólo son significativas para el individuo, sino que también están orientadas al otro. Si Husserl aporta el estilo formal apriorístico, los tipos ideales de Weber suministran el contenido empírico.

La teoría fenomenológica de la sociedad descansa, pues, en la intersubjetividad y ésta se explica fundamentalmente por la analogía del ego. En nuestros días, esta explicación cobra un valor de protesta; significa que, por muy reificadas que estén las relaciones humanas, este hecho sólo define un mal históri$\mathrm{Co}$, no su constitución primordial.

\section{La distancia de la fenomenología husserliana}

Merleau-Ponty realizó una revisión muy personal de la fenomenología de Husserl. No es éste el momento de referimos a ella; tan sólo aludiremos a aquellos puntos relacionados con la crítica de Merleau-Ponty a la teoría husserliana de la intersubjetividad, porque ambos filósofos consideran que ésta es la base del mundo social y que de su dilucidación depende también la de éste.

Merleau-Ponty intentó completar la teoría husserliana de la interrelación entre sujetos y aclarar cómo llegamos al otro en cuanto a subjetividad real (no sólo transcendentai). Merleau-Ponty pensaba que la distinción husserliana, dentro del ego transcendental, del ego propio y de la otredad era artificial. Es ininteligible cómo pueden constituirse otros egos absolutos como yoes dentro del campo transcendental, como correlato de mis actos transcendentales. Si únicamente la conciencia es la realidad autofundante, sólo podrá ser real mi conciencia. Ahora bien, Merleau-Ponty no había comprendido, quizás, que el argumento del solipsismo tiene en Husserl un papel comparable al malin génie de Descartes, es decir, es una suposición hiperbólica que nos ayuda a comprender cuan pobre de sentido sería una experiencia que sólo fuera mia, una experiencia al margen de la comunidad de hombres y de la naturaleza.

Husserl y Merleau-Ponty abordaron el problema de la intersubjetividad porque, aunque evidentemente hay otros hombres, es preciso también compren- 
der cómo y con qué sentido. Sólo una vez respondidas estas preguntas podremos construir un firme concepto de la sociedad. La diferencia entre ambos estriba en que Husserl parte de la subjetividad, mientras que Merleau-Ponty parte de la coexistencia. Considera que Husserl no resuelve el problema del paso de la conciencia de sí al otro e intenta transformar la enigmática intersubjetividad de Husserl en una intersubjetividad social e histórica. Emprende, además, una revalorización del mundo social que había descuidado el existencialismo y ve la relación yo-otro como inserción común en un mundo histórico y social en el que se realiza, pues "la fenomenología existencial es también fenomenología de la historian!

La fenomenología de Merleau-Ponty pretendió ser, en efecto, una interpretación crítica de los fenómenos sociales $y$, para ello, intentó superar la alternativa entre lo subjetivo y lo objetivo y volver a la única realidad colectiva. Sabemos que ésta no puede analizarse corno un objeto, tampoco es una mística conciencia colectiva, sino que es intersubjetividad, es decir, relación viviente y tensión hacia el otro. Por eso consideramos que los fenómenos sociológicos sólo son accesibles a una reflexión radical, a la comprensión. El sociólogo, pot tanto, no ha de hipostasiar los métodos explicativos, ya que su tarea principal no es la de determinar leyes, sino más bien la de comprender a los hombres como individualidades para entender sus acciones.

En una conferencia pronunciada en 1959 sobre la filosofia de la existencia, Merleau-Ponty elogiaba las aportaciones de la filosofia de Marcel destacando su tratamiento de las relaciones con el otro. Afirmaba que este tema no apareció en filosofía hasta finales del siglo XIX ${ }^{2}$. Merleau-Ponty piensa que el concepto de la intersubjetividad es inseparable del problema del otro, de la Lebenswelt compartida y de la historia. Esto es así debido a la complejidad misma de la cuestión, ya que no basta con decir que la sociedad se reduce a una suma de individualidades o que el individio es un simple producto social. Merleau-Ponty posee una concepción dialéctica de la sociedad en la que lo social es interior a lo individual y lo individual es interior a lo social; en otras palabras, todo es social y todo es individual. "No hay un hecho de psicología individual que no sea un hecho de psicología socialn ${ }^{3}$. Esto significa que la sociología y la psicología tienen objetos comunes: "la sociologia suministra hechos, la psicología permite comprenderlos" ${ }^{4}$. Hay una sola realidad en la que se mezclan cuerpos, almas, sociedad, etc. Hay fenómenos de totalidad. Como buen fenomenólogo, Merleau-Ponty concede cierta prioridad a la subjetividad sobre la objetividad, pero considera que la subjetividad más profunda coincide con

1. Véase, por ejemplo, CENTINEO, E. (1959). Una fenomenologia della historia. Palermo: Palumbo, 1959, p. 78.

2. Recogida en Dialogue $V$, n. 3 (1966).

3. Merleat-Ponty, M. (1964-65). "Merleau-Ponty à la Sorbonne", Bulletin de Pyychologie, 18, p. 219.

4. Ibidem, p. 224 
la socialidad, con las relaciones vivientes de todo singular $y$, en definitiva, con el ser-en-el-mundo que somos.

El conocimiento del mundo histórico-social implica, al mismo tiempo, la inmanencia y la transcendencia del yo y del mundo. Lo que da sentido al mundo y a nuestras acciones es la racionalidad y ésta se verifica realizándola. Al igual que su maestro, Merleau-Ponty no niega en absoluto la razón, pero tampoco quiere identificarla con una facultad dogmática. La tazón se va haciendo a través de nuestra existencia. Pero, ¿cómo se realiza la universalidad de la razón? Por el esfuerzo de los hombres hacia su unificación y hacia una comprensión mutua, hacia una armonía, un cierto consenso. El germen de la universalidad se halla en el diálogo y en el intento constante del yo de unirse con el mundo.

Por eso, en Merleau-Ponty, hay interrelación entre intersubjetividad y lenguaje. Aquélla es el medio en el que el habla se producirá, pero esta producción, a su vez, nos ofrece un universo en el que la preeminencia de la relación yo-otro sobre el plano egológico llega a su cumbre. Hablar y entender no son procesos que representen lo que se produce, sino que consisten en una intercorporeidad y una comunicación potencialmente universales. La expresión verbal instituye un nuevo mundo de comunicación en el que la relación con el otro no es sólo de participación en un mismo mundo, sino la presencia en acto de una relación en la que la expresión singular puede convertirse en un sentido universal. Hablar y comprender implican la capacidad de dejarse deshacer por un otro actual, por numerosos otros posibles y presumiblemente por todos. La palabra prolonga y transforma la muda relación con el otro, en ella se realiza el imposible acuerdo de dos totalidades rivales.

Sin embargo, nuestro filósofo está de acuerdo con Hussenl en que la intersubjetividad se constituye antes que el lenguaje; aquélla es la predisposición a éste y se proyecta a través de la historia y de la cultura. La primera palabra de la humanidad no se apoyaba en ninguna lengua establecida; esto significa que el principio de comunicación estaba ya dado de antemano. El lenguaje se sustenta, pues, en una serie de conductas comunes y en un mundo que no es en absoluto un mundo privado. No cabe duda, sin embargo, que el lenguaje es la operación gracias a la cual el pensamiento adquiere valor intersubjetivo. A través de él, el otro se convierte en alter ego, se hace plenamente significarivo.

A pesar de la importancia del lenguaje, Merleau-Ponty asegura que el yo encuentra al otro en la experiencia vivida. Somos dos conciencias en situaciones comunes. Gracias a las manifestaciones existenciales y a la posibilidad que tiene mi conciencia de reaccionar, puede acceder a la del otro sobre un fondo intersubjetivo, aunque el conocimiento lógico y absoluto de la conciencia del otro sea, por eso mismo, imposible de concebir. De este modo, Merleau-Ponty reconoce la imposibilidad de una completa explicación del fenómeno intersubjetivo.

Siguiendo a Husserl, Merleau-Ponty considera central el fenómeno del cuerpo propio para explorar la intersubjetividad. Conciencia y cuerpo están interrelacionados en el comportamiento. La conciencia que tenemos de nuestro 
cuerpo constituye un esquema corporal, es decir, una percepción de mi posición con relación a las coordenadas de su medio envolvente. A través de la imagen visual del Otro percibo que éste es también la envoltura visible de otro esquema corporal semejante al mío. La psicología evolutiva nos demuestra esta tesis y nos confirma que cuando el niño aprende a objetivar su cuerpo (en la imagen reflejada en el espejo), comienza a constituir al otro y sus diferencias con respecto a él. Para Merleau-Ponty, hay correlación entre la conciencia del cuerpo propio y la percepción del otro ${ }^{5}$, o lo que es lo mismo, la experiencia de mi cuerpo y la experiencia del otro forman una totalidad, una Gestalt. El mundo vivido es un mundo en el que el otro se nos da con evidencia, a diferencia de lo que piensa Husserl. Este se interrogaba por la conscitución del fenómeno de las otras subjetividades; Merleau-Ponty, en cambio, las toma como un dato preestablecido. Esto es así porque la fundación de la intersubjetividad, en Husserl, es paralela a la primacia del dominio transcendental sobre el dominio natural. En cambio, Merleau-Ponty busca la intersubjetividad en la percepción del otro más que en sus condiciones transcendentales de posibilidad, porque la percepción no es, para él, aprehersión de un objeto por un sujeto, sino que, en ella, el cuerpo aprehende la significación de los fenómenos que forman su mundo. La percepción de las conductas de un cuerpo no tiene que constituirse como percepción del otro yo en la vida del yo, sino como una manifestación de la vida del otro.

Esta orientación merleau-pontyana permite comprender la intersubjetividad según tres aspectos:

1. El fenómeno del cuerpo del otro se presenta como una especie de duplicado de mi vida corporal. La presencia del otro no se comprende, pues, a partir de la aparición de un objeto frente al sujeto consciente (esto no aclararía cómo un objeto percibido puede convertirse también en un sujeto perceptor), sino a partir de la manera que tiene el yo de descentrarse. De este modo, la presencia del otro es el término último de esta propagación.

2. Los otros se le dan directamente al yo. La percepción del otro no es, como quiere Husserl, una apresentación de la subjetividad a través de la presentación de aspectos que son fenómenos dados, sino la posición del otro implicada en una copercepción.

3. La apertura a una presencia común que hace posible el entrelazamiento de la experiencia del cuerpo propio y su repercusión en la percepción de otro. Dicha repercusión sería sólo una modificación interna del ego si no presupusiera un ser que engloba a éste y al otro: hay una generalidad primordial en la que el yo y el otro se confunden, hay algo que precede a la intersubjetividad, pero que no puede distinguirse de ella; en ese nivel, no hay individuación ni distinción numérica. La constitución del orro no sigue a la constitución del cuerpo, sino que el otro y mi cuerpo nacen conjun-

5. Merleau-PONTY, M. (1951). Les relations avec l'autrui obez l'enfant. Paris: CDU, p. 26. 
tamente en ese éxtasis original ${ }^{6}$ que sería la Carne. Metleau-Ponty recoge lo fundamental de las últimas obras husserlianas y transforma el Leib y el Leben husserlianos en Chair, porque la idealidad no puede existir sin encarnarse.

Por la percepción del otro, me encuentro en relación con otro yo mismo, con el mismo ser que yo. Desde el fondo de mi subjetividad, veo aparecer otra subjetividad con idénticos derechos, otro comportamiento que yo comprendo y que actúa, al igual que el mío, como centro de las intencionalidades hacia el mundo. Cuando observo otro cuerpo en su comportamiento, aprehendo una estructura bipolar, como la mía, que vive continuamente en un intercambio dialéctico entre su conciencia interior y el mundo exterior. Esto significa que Merleau-Ponty otorga al comportamiento vivido y al observado en el otro el mismo estatuto fenomenológico. Del mismo modo que mi cuerpo, como sistema de mis aprehensiones del mundo, funda la unidad de los objetos que percibo, el cuerpo del otro, en tanto que portador de conductas simbólicas, confiere a mis objetos la dimensión nueva del ser intersubjetivo o de la objetividad ${ }^{7}$. Para nuestro filósofo, al igual que para Husserl, intersubjetividad equivale a objetividad. Sin embargo, Merleau-Ponty no cree que sea la introducción del otro la que produzca la transcendencia objetiva, sino que el mundo está ya ahí antes que cualquiera de estos análisis, antes que ruestra propia reflexión sobre él.

¿Podemos decir que Merleau-Ponty afirma que el otro es un sujeto que yo pongo en el exterior como hago con el resto de los objetos? Merleau-Ponty no dice esto explícitamente, aunque reconoce que la ambigüedad es inevitable cuando intentamos comprender a los otros ${ }^{8}$, porque la propia condición humana es ambigua: el hombre es un interior inseparable de un exterior, un sujeto-objeto-en-el-mundo. Hay continua reciprocidad entre el yo y el otro: el sujeto se constituye en sociedad y ésta se inaugura en la intercorporeidad y en la percepción. La experiencia de la intercorporeidad es experiencia de intersubjetividad, ya que hay una transgresión intencional que, a través de la percepción del cuerpo del otro, me lleva a la totalidad hombre sin necesitar una mediación intelectual entre el yo y el otro. La raíz de lo social se halla en la dialécrica entre interioridad y exterioridad. Dicha dialéctica es lo que define al hombre mismo.

Tenemos una experiencia directa del otro a través de su comportamiento. Como ocurría en Husserl, estamos en relación con el otro por mediación del cuerpo. Sin embargo, el cuerpo no es algo objetivado. Entre el yo y el otro hay perpetua comunicación carnaldentro de un mundo común. A diferencia del objeto, que es agotable, el otro nunca lo es, siempre sigue siendo otro. Lo que sí es agotable es la experiencia que yo tengo de él. Para aprehender al otro he

6. Idem, Signes. Paris: Gallimard, 1960. p. 220.

7. MERLEAU-PONTY, M. (1989). Le primat de la preception. Grenoble: Gnara, p. 52-53.

8. Ibídem, p. 101. 
de distinguirlo de mí, he de situarlo en el mundo de las cosas y, al mismo tiempo, he de pensarlo como conciencia. Después de todo, si mi conciencia posee un cuerpo y sólo a través de éste cobra existencia y existen para ella las cosas, ¿por qué los otros no han de tener conciencia? La evidencia del otro es posible, en Merleau-Ponty, porque mi cuerpo no me permite contemplar el mundo como pura objetividad. Al no considerar el cuerpo como objeto, sino como comportamiento, la percepción del otro como tal se impone sin problemas a mi conciencia.

A diferencia de Husserl, la subjetividad transcendental merleau-pontyana supone la existencia empirica del yo y del otro y se construye con respecto a éstos. Precisamente la existencia - categoría fundamental para la fenomenología existencial- consiste en estar-en-el-mundo-y-con-los-otros. Esto quiere decir que mi existencia implica, sin más, la de los otros objetos y sujetos. Además la ek-sistencia se define como salir de sí, como transcendencia inmanente al mundo intersubjetivo o mundo de las coexistencias situadas en el único universo existente. En él descubro que las cosas no están ahí sólo para mí, que este mismo mundo que se ordena para mí de una manera peculiar, se organiza de otra (desde otro punto de vista) para el otro. Nuestra concepción del yo y de los otros deriva de un campo de experiencias parcialmente intersubjetivo que nos abre a un mundo común. Los otros son un horizonte permanente de mi existencia individual. De esta forma, se subraya la co-existencia yo-otro sin priorizar ninguno de los polos de esta relación. Mi existencia se caracteriza por su descentramiento, es decir, por estar situada entre la generalidad y la individualidad y mi experiencia se abre a otras experiencias que, por supuesto, incluyen las de los otros.

\section{El yo y el otro como comportamientos}

¿Qué experiencias tengo del otro sujeto? Sus acciones son un indicio de su existencia, aunque la prueba más evidente es su comportamiento. Además, el otro no es, como los objetos, sólo para mí, sino que, en tanto que es para mí, es ya para sí. Penetro en él a través de su comportamiento, es decir, a través de su participación activa en nuestro mundo.

Podríamos decir que Merleau-Ponty, como Husserl, prueba la existencia del otro por analogía con el comportamiento del ego; no obstante, la analogía merleau-pontyana no es un argumento o un razonamiento absoluto, sino un hecho. Su intersubjetividad es, en el fondo, intercorporeidad: mi cuerpo es el que me ofrece la presencia del otro. E. Bello ha caracterizado la filosofía de Merleau-Ponty como filosoffa de la relación ${ }^{2}$, como filosofía del encuentro; es más, su categoría central, la existencia, sólo se realiza en comunicación con los otros; la misma percepción es una forma de intercambio entre el sujeto y el mundo, es el suelo natal dei sentido. Por eso el otro es mi complemento en el 
mundo; es más, el ser sólo puede ser definido en términos de intersubjetividad; la posibilidad de la subjetividad presupone la intersubjetividad y no a la inversa, como parecía ocurtir en Husserl.

Efectivamente, el punto de partida de Merleatu-Ponty es la relación como algo ya dado. Así, por ejemplo, afirma que para instaurar significaciones, el cuerpo necesita al otro. La pluralidad de existencias no supone, pues, ninguna inferencia, simplemente se experimenta de manera directa e irrefleja. Pluralidad no equivale, empero, a reversibilidad: que podamos ser varios no significa que podamos ser el otro, no podemos penetrar totalmente en él, porque vivimos como formas peculiares de comprometernos con la situación.

Del mismo modo que mi cuerpo es, a la vez, objeto para otro y sujeto para mí, hay dialéctica entre la existencia individual y la coexistencia social. Esta dialéctica no implica contradicción, sino tensión entre dos existencias que se afirman negándose. El otro no es la regación de mi yo, sino la entrada de éste en la constelación de la alteridad. Por eso lo social se diferencia de lo natural: no existe en tercera persona, sino en el seno de un ámbito de coexistencia. Lo social no es una cosa, sino una forma; pertenece a la Lebenswelt. El ser del otro no consiste en ser constituido por mí en la síntesis de mis vivencias. No hay sujeto transcendental fuera del mundo, no hay cogito separado de una situación. De este modo, Merleatu-Ponty da carne a la intersubjetividad de Husserl: los otros son carne de mi carne ${ }^{10}$.

Al comenzar reconociendo a los otros, se afirma que se es otro que los otros, se demuestra el ego. Guardo una relación distante con ellos, pero verdadera; somos capaces de salir de nuestro reducto, pero el otro siempre continúa siendo tal, porque "el verdadero sujeto es sin segundo" ". He ahí un nuevo ejemplo de la tensión que caracteriza toda la filosofía merleau-pontyana.

Incluso mi propio pensamiento - aquello que en Descartes evidenciaba mi existencia - me habla de la existencia del otro. Esto nos demuestra que el solus ipse es un sujeto construido y no un dato de nuestra experiencia. La verdadera y transcendental soledad sólo tiene lugar si el otro es inconcebible y no existe un ego capaz de afirmar esto. Por consiguiente, el solipsismo niega, a la vez, al ego y al $i p s e$. La esfera solipsística no puede postularse absolutamente porque sería ininteligible: anteriormente a cualquier juicio hay un mundo social, dialógico en el que la alteridad es constitutiva. La soledad de la que emerge el yo y que lo conduce a la vida intersubjetiva no es la de la mónada.

La existencia del otro es un hecho, pero un hecho para mí, está entre mis propias posibilidades y sólo tiene el valor de hecho porque es vivida y comprendida por mí. Me resulta imposible vivir la presencia del otro tal y como es para sí mismo. Sólo lo experimento a través de mi cuerpo, pero esto no significa que sea yo quien lo constituya. El otro existe para mi como medio de coexistencia irrenunciable; el otro y yo, soledad y comunicación son momen- 
tos de un único fenómeno. Es preciso que mi experiencia me dé de alguna forma al otro, porque, de lo contrario, la misma palabra soledad carecería de sentido.

Merleau-Ponty es consciente de que, tanto el racionalismo como el empirismo, se quedan en el solipsismo. El primero parte del presupuesto de una conciencia constituyente y convierte el cuerpo en objeto del pensamiento; de ahí que, para él, sea inconcebible la pluralidad de conciencias: para una conciencia constitutiva, el cuerpo es tan sólo un objeto. El empirismo, por su parte, no va más allà de la experiencia privada $y$, por consiguiente, es incapaz de comprender la experiencia del otro. Ambas tendencias no han podido liberarse del sualismo conciencia-objeto. Sin embargo, el sentido común comprende que el mundo que yo percibo no puede estar clausurado en mi punto de vista y que es preciso que haya otros sujetos perceptores.

Merleau-Ponty no cree que el otro surja simplemente de la experiencia que yo tengo de él, pero está convencido de que sólo de ésta nace el sentido que ese otro tiene para mí. La presencia del otro es un dato irrefutable, pero, ¿cómo salgo de mí para acceder a él? Para responder a este interrogante, MerleauPonty no se contenta con la idea sartriana de la relación yo-otro como una alienación reciproca (cada uno es meramente un objeto para la conciencia del otro). Él está convencido de que no hay soledad absoluta, pero tampoco comunicación total. Nuestra existencia tiene una dimensión social porque existimos en un mundo cultural, porque el sentido de mi vida depende de mi presente, de mi pasado y también de las relaciones que establezco con los otros.

Merleau-Ponty piensa que hay una correspondencia global (no parcial) entre la imagen del cuerpo del otro y la imagen introceptiva de mi propio cuerpo. Si tenemos en cuenta el carácter intencional de la conciencia quedan superadas las dificultades de la psicología clásica, ya que constatamos que la conciencia es un continuo interrelacionarse con el mundo y con los otros.

Así pues, el mundo social es nuestro horizonte simpre presente. Antes de cualquier objetivación o de caulquier reflexión, ya estamos en lo social. El verdadero transcendental de Merleau-Ponty es esa vida plena de ambiguiedades, la Lebenswelt, que no es el ser puro, sino el sentido que se teje en la intersección de mis experiencias y en el nudo de mis experiencias con las del otro. Los otros son, pues, las coordenadas permanentes de nuestra vida. Es más, la verdad es el yo con los otros en el mundo, en el devenir incesante de la historia y de la sociedad. Aunque la verdad se encuentra presente de modo informe en el sujeto singular, su cuna está en la intersubjetividad.

\section{Crítica de la teoría sartreana del alter ego}

El otro, en cuanto que se halla en mi campo perceptivo, no es un yo en el mismo sentido en que yo lo soy para mí; si deseo pensarlo como un yo, es necesario que yo me piense primero como objeto para él. Ésta sería la idea de Sartre. Para él, como para Heidegger, la comunicación está destinada a afirmarse a mí y a negar al otro. 
Sarte fue otro de los más destacados fenomenólogos existenciales que abordó el problema del otro y sus múltiples manifestaciones ${ }^{12}$. Rechazaba tanto el intento realista como el idealista de probar la existencia humana del otro. El realista postula el modo externo como real y, dentro de él, el cuerpo del otro como algo dado. Sin embargo, nunca puede probar que este cuerpo sea más que un cuerpo, que sea el cuerpo de un semejante, a menos que parta de la existencia de la mente del otro como una certeza. En ocasiones, el realista afirma la existencia del otro como cierta, aunque admita que nuestro conocimiento de el es una mera probabilidad. Nuestro conocimiento de la mente del otro se revela, para este realista, mediante el razonamiento por analogía, empatía o simpatía. No obstante, la existencia humana del otro siguie siendo un hecho puramente conjerural.

Para el idealista, el otro sólo es lo que presenta ante un yo, pero sabemos que aparece en formas organizadas tales como gestos, acciones, expresiones o conducras. Estas formas se refieren a una entidad organizadora colocada más allá de mi experiencia e inaccesible esencialmente para mí. Además, el idealista no puede explicar por qué el otro es una unidad sintética de sus experiencias y cómo organiza mis experiencias sobre él.

Otro problema importante que se le plantea al idealismo es el de la unificación del tiempo de nuestros flujos de conciencia. ¿Hemos de presuponer que mi conciencia unifica su tiempo y el de la otra conciencia? Mi tiempo interior no parece estar vinculado la tiempo interior de la conciencia del otro, a menos que se suponga una extraña armonía preestablecida. Aún adoptando este supuesto, los dos flujos de conciencia permanecen inconexos, puesto que para cualquiera de ellas, la sintesis unificadora de momentos en un flujo se origina en un acto de la propia subjetividad. No es el otro el que constituye la experienica que yo tengo de él, sino que un cierto tipo de mis experiencias me induce a constituir al otro como sujeto. En efecto, a través de mis experiencias del otro contemplo sus sentimientos y acciones. El otro no es solamente aquél a quien veo, sino también aquél que me ve. Yo lo contemplo como un objeto entre otros que forman parte de mi mundo. Si pretendo establecer la naturaleza concreta de su sistema de experiencias y mi lugar en él, debo transcender el campo de mis propias experiencias y destruir la unidad de mi conciencia. Para Sartre, pues, la noción del Otro no puede ser interpretada, tal y como ocurre en el idealismo, como una idea reguladora. El dilema del idealismo es que concibe al otro como un objeto de mi pensamiento, pero ha de postularlo, al mismo tiempo, como sujeto. Los idealistas intentan solucionar el dilema de dos modos: o bien abandonan la noción de otro demostrando que es innecesaria para la constitución de la experiencia propia, o bien postulan una comunicación real y extraempírica entre mi conciencia y la del otro. El primer intento conduce al solipsismo y el segundo, a la interpretación existencialista de Sartre. 
El realista afirma generalmente que existen plurales sistemas de experiencias, no interrelacionados y totalmente exteriores entre sí. De este modo, presupone que el otro se aparece con ocasión de la percepción que tengo de su cuerpo; éste se hallaría separado del sujeto perceptor de la misma forma que los objetos lo están del mundo externo. También el idealista presupone una distancia espacial entre los dos flujos de conciencia, uno de los cuales es exterior al otro. De esta forma, sólo un observador, externo a mí y al otro, podría discernir la verdad de la coexistencia del yo-otro. Este supuesto conduciría a un regreso al infinito que, probablemente, seria superado por la noción teológica de Dios, el verdadero Otro.

No puede decirse con rigor que Husserl adopte la vía idealista y, por lo tanto, caiga en el solipsismo, ya que incluso en sus primeros escritos aparece ya el problema de la intersubjetividad; además, Husserl no se interesa por la constitución de nuestra experiencia individual, sino por la constitución de la realidad, por el problema de la objetividad del mundo, y este problema se halla entrelazado con el tema de la intersubjetividad. Por otra parte, en Husserl, la comunicación y la intersubjetividad no son postuladas, sino que se presuposen siempre en la actitud natural; si la reflexión filosófica coloca entre paréntesis esas realidades ineludibles, lo hace para analizar mejor y descubrir sus fundamentos y sus orígenes, no para demostrar su irrelevancia.

Sartre opina, por el contrario, que el intento husserliano de evitar el solipsismo es un fracaso y que su teoría de la intersubjetividad es inferior a la teoría elaborada por Hegel. En éste, la noción del otro es indispensable para la consititución del mundo, de mi ego empírico y de mi autoconciencia. Por el hecho de ser yo mismo, excluyo al otro; por el hecho de ser él mismo, el otro, a quien yo excluyo, me excluye. Hegel, a diferencia de Husserl, evita establecer una relación unfvoca entre el ego cogito y el otro. Supone desde el comienzo una relación reciproca, definida como aprehensión del sí mismo de uno en el sí mismo del otro. La existencia del otro es la condición para la aprehensión del sí mismo por sí mismo, y esto es, a la vez, la condición para cualquier cogito. De esta manera parece evitarse todo resto de solipsismo: mi autoconciencia depende de la realidad de otro, y la autoconciencia del otro depende de $\mathrm{mi}$ propia realidad. Sin embargo, la conciencia es, para Sartre, una noción totalmente vacía, una pura nada y no debe identificarse con la conciencia concreta que tengo del mundo, de mímismo o del otro.

Hegel es víctima de un optimismo epistemológico, es decir, presupone un acuerdo entre mi conciencia y la del otro, entre mi reconocimiento por el otro y el reconocimiento del otro por mí. Pero lo que yo soy para el otro, lo que él es para mí, lo que yo soy para mí mismo y lo que él es para sí mismo no son cosas conmensurables. Yo experimento mi sí mismo y él experimenta el suyo como sujetos, pero experimentamos el yo del otro como un objeto. ¿Cómo podré reconocerme en el otro si éste es, ante todo, un objeto para mí? ¿Cómo podré captar al otro como él es realmente para sí, es decir, como sujeto? Sartre denomina a esta situación aparentemente insalvable la separación ontológica del uno y del otro. 
Además Hegel es víctima de un optimismo ontológico, porque supone que la relación entre las conciencias puede ser estudiada como tal, sin tomar como punto de partida y sistema de referencia una conciencia particular concreta. Hegel no analiza la relación entre el ego y el alter ego, se limita a estudiar las interacciones vigentes entre las conciencias de otros, reducidos a meros objetos. Lo único que consigue es describir el escándalo de la pluralidad de conciencias, pero no superarlo.

Sarte piensa que Heidegger tampoco nos ayuda a superar el solipsismo, porque se limita a establecer entre el yo y el otro una relación de ser, afirma que la realidad humana es desde el comienzo Mitsein. Esta es una estructura particular de mi propio ser, por lo tanto, el otro no es una existencia particular que yo encuentro dentro del mundo, sino el término ex-céntrico que contribuye a mi propia existencia. En el estado de inautenticidad de la vida cotidiana realizo mi ser con otros no como una relación de conocimiento mutuo, sino en la forma de anonimato. Identifico al otro con el Uno (Man). En este estado inauténtico no soy un sí-mismo: sólo cuando me sé determinado hacia la muerte alcanzo ese estado auténtico. Si, como piensa Heidegger, la relación ontológica entre el yo y el otro tiene carácter aptiorístico, ¿este a priori no será válido únicamente dentro de los límites de mi experiencia? ¿Mi estar concreto con el otro no transciende mi experiencia? El Mitsein, como el ego husserliano, aún considera la realidad humana concreta como un elemento constitutivo del yo.

Sartre construye una teoría que no necesita probar la existencia del otro, cuya afirmación se basa en una comprensión preontológica. El otro no debe ser captado como un objeto de nuestras cogitaciones, sino en su existencia pata nosotros, en cuanto afecta a nuestro ser concreto. El otro es un no-yo. Esto significa que hay una relación activa entre dos términos, cualquiera de los cuales se constituye negando al otro.

La apatición del otro rompe la unidad aparente de mi universo; a partir de entonces, percibo los objetos como no sólo percibidos por mí, sino también por él. El otro se distingue de todos los demás objetos por el hecho de que es el objeto que percibe lo que yo percibo y es capaz de percibirme como un objeto. ¿Cómo puedo ser el objeto de un sujeto si nunca puedo ser un objeto para mí mismo? Cuando veo al otro presupongo que puedo ser visto por él. El otro es el que me mira. Si otro me mira, me vuelvo autoconsciente, es decir, advierto que soy un objeto para él y, además, ya no soy yo mismo sino por referencia a otro que limita mi libertad. Comprendo esta experiencia, no mediante la cognición, sino por un sentimiento de inquietud o incomodidad que, según Sartre, es uno de los rasgos de la condición humana. Mi ser-para-mí-mismo es, pues, desde el comienzo, ser-para-otro. Una vez constituido el otro como una subjetividad, puedo convertirlo nuevamente en objeto. Sólo puedo conocer como totalidad coextensa dentro del mundo al otro como objeto; el otro-sujeto nunca puede ser objeto de ningún tipo de conocimiento. Cuando convierto al otro en objeto, recupero mi subjetividad. El otro es un objeto para mí tan sólo en la medida en que yo soy un 
objeto para él. El tipo de objetivación del otro depende de la relación entre nuestros cuetpos.

Sartre distingue tres dimensiones ontológicas dentro de mi propio cuerpo:

1. Mi cuerpo en su ser fáctico ${ }^{13}$. Experimento mi cuerpo como centro de referencia y orientación, como instrumento de mis acciones, capaz de manejar todos los instrumentos. Sin embargo, no mamejo mi mano, sino que soy mi mano. Mi cuerpo determina mi punto de vista y el punto de partida de mis posibilidades. Esto significa que mi cuerpo es conciencia.

2. Mi cuerpo en su ser-para-el-otro, tal como es utilizado y conocido por el otro $^{14}$. Según Sartre, el otro existe para mí primero y sólo después lo capto en su cuerpo. A diferencia de mi propio cuerpo, el suyo tiene el carácter de una estructura secundaria. Es, para mí, un instrumento. El cuerpo del otro es la totalidad de sus relaciones significantes con el mundo.

3. Mi experiencia de mí mismo como ser conocido por el otro gracias a mi cuerpo $^{15}$. Cuando el otro me mira, mi cuexpo ya no determina exclusivamente mi punto de vista; el otro tiene una perspectiva de él y hasta una perspectiva que yo mismo no puedo tener. El otro me ve como soy. Gracias a él, llego a captarme con sus ojos, dejo de experimentar el ser de mi propio cuerpo y comienzo a tener cognición de él. En este nivel tiene lugar la asimilación del cuerpo del orro a mi propio cuerpo mediamte la analogía: mi cuerpo para el otro es lo que el cuerpo del otro para mí. Sin embargo, la analogia no puede constituir originalmente al objeto-cuerpo del otro y la objetividad de mi propio cuerpo. Estas dos objetividades deben ser presupuestas antes de que intervenga el principio de analogia. Primero debo objetivar mi cuerpo. La noción que yo tengo de mi cuetpo nunca será reconciliable con el ser fáctico de mi cuerpo en su ser mismo.

Sartre critica la teoría de la intersubjerividad de Husserl porque se limita a relacionar sujetos transcendentales. Habla con frecuencia del universo intermonádico y esto quiere decir que presupone una pluralidad de egos transcendentales. Sin embargo, no logra conciliar la noción de ego transcendental (fuente de constitución del mundo) con la de pluralidad de sujetos transcendentales coexistentes. La quinta meditación cartesiana de Husserl no nos muestra cómo el otro se constituye como ego transcendental, sino sólo de qué modo él es constituido como una unidad psicofísica mundana. A pesar de estas críticas, los propios análisis sartreanos del cuerpo deben más a las enseñanzas de Husserl de lo que pudiera suponerse.

A pesar de todo, Sartre tiene razón en algunos aspectos que se han convertido en las claves de la crítica a la intersubjetividad husserliana. Así ocurre, por ejemplo, con el fenómeno de Paarung y la comunidad de egos transcendenta-

13. J.P. SARTRE, Lêtre et le néant. 368-404.

14. Ibídem, p. 404.418

15. Ibidem, p. $418-428$ 
les: el término apresentante del par husserliano no es mi ego transcendental, sino mi propia vida autodada como un yo psicofísico. Lo que es apresentado en el Paarung es el objeto del mundo externo interpretado como cuerpo de otro ser humano, el cual indica la vida mental del otro, peto del otro como una unidad imtramundana y no como alter ego transcendental. Hubiera sido preciso que Husserl mostrara la posibilidad de ese alter ego transcendental constituido dentro del ego transcendental para superar el argumento solipsista en la esfera transcendental.

La teoría de Sartre no aspira a probar la existencia del otro, ya que nuestra creencia en ella está arraigada, como decíamos, en una comprensión preontológica. Su explicación parece una prolongación de la dialéctica hegeliana de la relación entre el amo y el esclavo, en la cual se entiende que ambos elementos pueden intercambiar sus roles en cualquier instante. Señala, sin embargo, que la relación entre un yo-sujeto y un otro-sujeto es imposible: o bien yo soy el sujeto y el otro el objeto o viceversa ${ }^{16}$.

Sartre es víctima del optimismo hegeliano: presupone que mi experiencia del otro y la experiencia que el otro tiene de mí son intercambiables. Así, en lugar de analizar el significado que mi cuerpo tiene para el otro, analiza el significado que el cuerpo del otro tiene para míl7. Dice además que, al convertir en objeto al otro, éste es un objeto para mí simplemente en la medida en que yo soy un objeto para él ${ }^{18}$. Sartre sustituye el análisis de la constitución del otro por el problema de la intercambiabilidad. Coincidimos con él en cuanto a que la existencia del otro no necesita probarse. Sin embargo, creemos que debería haber demostrado cómo se llega a la comprensión de la conducta del otro concreto sin caer en el argumento solipsista.

En efecto, si seguimos sus pasos, nunca podremos conocer al otro sujeto como tal. Los objetos de este mundo no se refieren a ese otro-sujeto, sino al otro-objeto. Cuando me mira, me convierto en objeto para el otro-sujeto que nunca puede ser captado por mí como tal. ¿Cómo es, entonces, posible la intercambiabilidad de mi experiencia del otro y de su experienica de mí?

La teoría sartreana del alter ego está prisionera de concepto de acción débil. Mediante mi acción capto una de las posibilidades y me comprometo con un proyecto elegido. Con la aparición del otro esta estructura organizada se desarma y surge una subestructura de posibilidades prácticas que ni ha sido creada ni elegida por mí, sino por él. Por eso las posibilidadees de la libertad del orro constituyen el límite de las mías. Pero ¿cómo puedo discernir el ámbito de las posibilidades prácticas del otro? Además, el otro-objeto (el único al que puedo acceder) carece de libertad de acción. Mi acción tiene un sentido muy distinto para mí que la acción del otro. ¿Por qué, entonces, suponer que el otro actúa, que tiene posibilidades abiertas como yo, que tiene libertad?; ¿cómo podemos liegar a una comprensión de lo que significa la acción del otro para él, el actor?

16. Ibidem, p. 430.

17. Ibídem, p. 405 . Véase también nota 16.

18. Ibidem, p. 356. 
¿Cómo relacionaremos nuestra conducta con la del otro? ¿Cómo explicamos la acción y la relación social?

La crítica de Merleau-Ponty a estas afirmaciones es esencialmente la siguiente: no hay libertad incondicionada. Si en Sartre la libertad del sujeto se afirma a pesar de la alteridad, en Merleau-Ponty la libertad del sujeto se logra gracias a la alteridad: la libertad ajena confirma la mía, aunque asi la limite, y la confirma precisamente como la libertad limitada. Merleau-Ponty nos propone la dialéctica conciencia-mundo, ego-alter, solipsismo-comunicación.

Da la impresión de que el concepto de situación y libertad de acción que presenta Sartre no describa adecuadamente la realidad humana. En la esfera mundana de la vida cotidiana, me concibo a mí mismo y al otro como centro de actividad. Cada uno de nosotros define su situación. Lo que es significativo para el otro no siempre coincide con lo que es significativo para mí, aunque sólo sea porque yo estoy Aquí y él Allí. Sir embargo, el reconocimiento de que el otro vive en un escenario no definido por mí, no lo convierte sin más en utensilio mío. Permanece dentro de su situación como centro de sus actividades y yo puedo comprenderlo como siendo yo, sus actividades como no siendo las mías, sus instrumentos como estando más allà de mi alcance, etc. ¿Se deduce de esto que sólo puedo tener una comprensión negativa del otro? Para interpretar las acciones de los otros necesito comprender el significado que ellos les otorgan, pero eso no es un obstáculo.

Admitimos que las teorías de la empatía, la simpatía y el razonamiento por analogía son intentos insatisfactorios de resolver el problema porque postulan que tenemos que comprender lo que el otro entiende por su acción, del mismo modo que yo comprenderf́a mi propia acción análoga, en términos de mi sistema de significatividades, si yo estuviera alli (en lugar del otro) en vez de estar aquí. Sartre no explica ninguno de estos viejos problemas. La magia de la mirada del otro no consigue suministrar una respuesta adecuada.

Hubiera sido más efectivo recurrir a la comunicación porque, de hecho, la actividad de un sujeto al hablar presupone siempre la actividad de orro que le escucha y viceversa. Ambos se aprehenden el uno al otro como una subjetividad coefectuada. Esto significa que, de alguna manera, el tiempo interior del sujeto A puede conectarse con simultaneidad con el tiempo interior del sujeto $\mathrm{B}$, es más, que el diálogo y la relación constituyen las acciones humanas. Frente a esta idea, Sartre no dejaba espacio en su filosofía para la interacción murua en la libertad: o bien el otro me mira y aliena mi libertad, o bien asimilo la libertad del otro. Su universo era dualista y, lógicamente, no podía dar cumplida cuenta de la intersubjetividad.

Cuando Sartre dice en El ser y la nada que el orro roba el mundo al yo, no reconoce la premisa husserliana de que la transcendentalidad de la dirección del yo hacia el otro puede abrir la objetividad del mundo en su validez intersubjetiva. Sartre piensa la relación entre sujetos como una relación dialéctica entre yo y no-yo. ¿Como podrá darse, entonces, la intersubjetividad? Además, el otro nunca es un no-yo a la manea de los objetos, sino otro-yo; sus perspectivas no niegan las mias, sino que las complementan. 
Si se parte del yo transcendental, como hace Husserl, no se puede decir que el otro le roba el mundo al descentrarlo con telación a él, pues la transcendentalidad del yo (su intersubjetividad transcendental) va más allá del aquí de cualquier centralización empírica. Pero, ¿qué relación hay, entonces, entre ese yo transcendental y el yo empírico? Esta es la pregunta fundamental que nosotros le planteábarnos a Husserl.

En términos sartreanos, sólo podemos decir que el otro se me da como un objeto que probablemente es un sujeto. ¿Cómo descubro al otro como sujeto? Cuando miro al otro actúo como sujeto, pero convierto al otro en objeto. Cuando soy mirado por él, lo experimento como sujeto. El conocimiento de la subjetividad del otro desde otra subjetividad cognoscente es, pues, imposible.

El cuerpo es mi acceso al otro y, a la vez, el otro es la ocasión para tomar conciencia de mi cuerpo. ¿Cuál es la función del otro en relación con mi cuerpo? El otro no es, como piensa Sartre, el que me recuerda la dimensión alienante de mi cuerpo. Es cierto que el hecho de tener un cuerpo me hace vulnerable a la mirada de los demás y que, para apropiarme de mi cuerpo, necesito la estimulación activa y hasta el permiso del otro. No obstante, creemos que la mirada entre dos sujeros no conduce necesariamente a la objetivación, sino que también puede ayudar a promover nuestra subjetividad y aceptar nuestro cuerpo y nuestra finitud y, en definitiva, a superar nuestra alienación. El cuerpo no es nuestra caída, sino nuestra condición humana. Quizás deberiamos retornar al Hegel que afirmaba que el requisito de la autoconciencia es el reconocimiento mutuo. No somos sólo para-el-otro, sino también para-nosotros-mismos; para lograr esto último, necesitamos la mediación del otro.

Finalmente digamos que la teoría sartreana concede primacía a la mirada, pero su análisis de esta no garantiza la posibilidad de una verdadera intersubjetividad y tampoco de una auténtica subjetividad, ya que la subjetividad real es posible en el contexto de la intersubjetividad porque yo necesito al otro para que interactúe con mi propio cuerpo. El otro no es el enemigo de mi subjetividad, sino la condición de ésta. Es verdad que la mirada adquiere un papel importante en la mediación entre yo y mi cuerpo con la ayuda del otro; sin embargo, hay que añadir que la función de la mirada es similar a la del tacto, el sonido y la dialéctica del deseo humano.

Merleau-Ponty nos diría que Sartre no puede justificar al otro, porque concibe la conciencia como algo absoluto. Si el cuerpo del otro no es un simple objeto-para-mí ni el mío es tal para él, seremos dos comportamientos, no dos objetos. Yo no soy un yo absoluto, sino una existencia limitada, una intencionalidad. Soy con otro y lo que me caracteriza es ese movimiento hacia el otro, que es una prolongación de mis intenciones. No hay autoconciencia ni comunicación privadas. La pluraliad constitutiva de los yo no excluye, sin embargo, la individualidad y la originalidad de cada uno. Soledad y comunidad son dos momentos dialécticos de nuestra vida, porque el otro es, a la vez, inmanente y transcendente para mí. Merleau-Ponty pretende, como Sartre, fundar 
un humanismo existencial, pero no se ve su posibilidad si se presenta la alteridad como infrerno. Sartre se ha olvidado de la dialéctica humana, de que otro es para mí el tormento y la gloria, el infierno y el paraíso.

Así pues, el otro es tan evidente como la percepción que yo tengo de él; ésta es indudable y anterior a toda analogía; gracias a ella, sentimos inmediatamente que coexistimos con los otros. Merleau-Ponty pretende superar el dualismo sartreano del en-sí y del para-sí mediante la percepción del otro, en la cual el en-sí se halla unido intencionalmente al para-sí. La oposición irreductible de Sartre deriva de la irreductibilidad de la oposición sartreana entre mi cuerpo (cuerpo-sujeto) y el cuerpo del otro (cuerpo-objeto).

\section{La Carne: intersubjetividad como fenómeno originario}

El primado merleau-pontyano de la percepción está íntimamente relacionado, como acabamos de ver, con el tema de la intersubjetividad. Percibir es contactar con la diferencia: percibo al otro y puedo ser percibido por él, pero el perceptor se diferencia, en este mismo acto, del ser percibido; hay contacto porque hay reversibilidad, pero hay diferenciación.

La sola presencia del mundo cultural requiere una experiencia vivida de la intersubjetividad, por eso en Le Visible et l'Invisible, Merleau-Ponty afirmará que no existe problema del alter ego ${ }^{19}$. En esta obra, Merleau-Ponty desarrolla una filosofía de la presencia como profundidad ontológica de la estructura subjetivo-objetiva del acto del uno-frente-al-otro y de la dimensión intrínsecamente intersubjetiva del significado. La mirada se agrega a la corporeidad al hacerse instrumento de conocimiento del otro y del diálogo; la mirada misma es lenguaje y expresividad. La visión es así un acto perfectamente comparable con la palabra: del mismo modo que percibimos en el acto de ver, gracias a la luz, pensamos en el acto de hablar, gracias al otro; del mismo modo que la luz es condición de posibilidad de la visión, la intersubjetividad transcendental posibilita el lenguaje. En esta última etapa, el concepto clave de su filosofia es el de carne o reversibilidad. Dicho término es caracterizado siempre mediante metáforas e imágenes que expresan duplicidad: dentro y fuera, anverso y reverso, identidad y diferencia, sensación e intelección, yo y otro, etc. La pregunta que podemos hacernos ahora es la siguiente: ¿es suficiente la alteridad reversible del sintiente y de lo sentido, del vidente y de lo visible, que descubrimos a través del cuerpo propio, para comprender la alteridad de las otras personas y del mundo objetivo? Merleau-Ponty contestaría afrmativamente porque la propiedad primordial de la Carne es la visibilidad, la cual nos habita a todos los seres ya que irradia por todas partes. El yo y el otro nacen conjuntamente gracias a ese éxtasis original, a esa capa de anonimato transcendental de la que surgen todas las cosas, a la Carne. Este es el parentesco que tengo en común con los otros y por él tenemos un mismo mundo. 
Al tener el cuerpo propio como un tercer género de ser (distinto del ser-ensí y del ser-para-sí), Merleau-Ponty evita la comprensión del cuerpo propio y del ajeno como objetos. Mi cuerpo y el del otro forman una sola estructura circular, porque pasan por el mundo y, en el fondo de su ser, son relación. ¿ No resulta negada así la subjetividad y afirmada la vida general y anónima que no puede constituir una verdadera intersubjetividad? Merleau-Ponty no explica el surgimiento de la conciencia de sí y del otro partiendo de ese fondo de indiferenciación primitiva, no desea negar la individualización de las conciencias, pero tampoco absolutizarla. Creemos que su obra da cumplida cuenta de la subjetividad y no contribuye en absoluto a negarla.

Es verdad que hay un fondo de semejanza, una matriz polimorfa de la que emergen tanto el yo como los otros, pero la relación yo-otro se da entre papeles complementarios que se necesitan mutuamente para existir. Puesto que lo verdaderamente existente es el Ser Vertical o la Carne, no soy yo el que constituyo al otro frente a mí, sino que el otro está ya ahí conmigo y el ego se conquista gracias a el. El otro es leiblich en esa carne que excluye la separación entre alma y cuerpo; su presencia es paradojica, ya que es presencia de una cierta ausencia en la que también yo soy. Merleaut-Ponty piensa ahora en una intersubjetividad vertical, no perspectivística, en una eternidad existencial.

Merleau-Ponty considera que el problema yo-otro es típicamente occiden$\mathrm{ta}^{20}$, incluso absurdo, porque el conocimiento del otro surge sobre algo ya constituido, sobre un campo, y esto es lo que hay verdaderamente. El yo y el otro están separados por la misma superficie que constituye su unión, por una bisagra en la que giran mi vida y la de él interpenetrándose; esta especie de bisagra es el armazón de la intersubjetividad ${ }^{21}$, la estructura carnal primera en la que reposan todas las interrelaciones humanas y la sociedad entera.

Podríamos decir que, en realidad, Merleau-Ponty no pretende resolver el problema del otro, sino transformarlo. Para ello, construye una nueva noción de subjetividad como contacto con el ser a través de sus distintas modulaciones o relieves. De esta forma, el otro deja de concebirse como una libertad exterior opuesta a la mía; ahora se entiende, al igual que nosotros, como parte del mundo y, por tanto, como parte nuestra, porque el mundo es común: "Hay transitividad por generalidad ${ }^{22}$ ¿Retorna así Merleau-Ponty a la vieja e insuficiente noción de empatfa? En todo caso, sólo tangencialmente; la empatía no es, para él, una forma de dar cuenta de nuestras relaciones con los otros, sino una de las muchas características de esta situación que, como hemos visto, no requiere demostración. Es cierto que Merleats-Ponty admite que hay analogía entre la primacía de la percepción en el ámbito cognitivo y la primacía de la empatía en las telaciones afectivas. Este postulado está estrecha-

20. Ibídem, p. 274. Con esto alude Merleatt-Ponty a esa fusión del yo individual del yo universal o cosmico que existe en la filosoffa oriental.

21. Ibídem, p. 287.

22. Ibidem, p. 322 . 
mente ligado a la primacía de la intencionalidad operativa, la cual significa que el mundo de la vida es el origen de la distinción temática derivada entre mi subjetividad constituyente y los objetos intencionales. Del mismo modo que la fenomenología se funda en la ontología, la empatía primordial es la base de las relaciones humanas deliberadas y téticas. La empatía en el adulto no disuelve las diferencias entre el yo y el otro; esto puede comprobarse en el amor: amat es entrar a formar parte de una situación indivisa con el otro. En este sentido, amar implica siempre una cierta alienación, ya que se vive en las intenciones del otro, el ego es desposeido legítimamente por el orro; mi idenridad se constiruye exigiendo la del otro y nuestra reciprocidad no anula nuestras diferencias.

La fenomenología del amor de Merleau-Ponty es una indicación de su posición frente a la alteridad. La empatía, el amor, la existencia vivida expresan significaciones que yo no constituyo, sino que forman mi identidad y el campo en el que puedo establecer deliberadamente relaciones con los otros. MerleauPonty piensa que la intersubjetividad sólo se convierte en paradoja para una filosofía que concibe abstractamente al sujeto como un objeto. En cambio afirma que lo humano emerge de una situación anónima previa en la que no me conozco a mí mismo ni al otro, sino que vivo en ambos. Esa empatía primordial o esa sociabilidad sincrética es anterior a cualquier acto tético. Frente a Husserl, que abordaba la intersubjetividad como un problema de conocimiento, Merleau-Ponty recupera el valor de la afectividad para esclarecer este concepto.

Leviras se opone a esta explicación merleau-pontyana de la alteridad centrada en la primacía de la empatía y de la percepción. La alternativa que él nos ofrece consiste en afirmar que la aproximación al otro se realiza a través del sentimiento ${ }^{23}$. Así, el amor, y especialmente el amor de Dios, sería el prototipo de cualquier relación de reversibilidad. Frente a Merleau-Ponty, Lévinas opina que la reversibilidad no equivale a sustituibilidad, sino a intercambiabilidad con diferencias porque la relación yo-otro es asimétrica.

En nuestra opinión, la relación yo-otro en Merleau-Ponty también reúne estas características. El yo y el otro no son homogéneos, pero tampoco son completamente heterogéneos. La relación entre ambos no se reduce sin más a la sensación o a la primacía de la percepción, ni excluye dimensiones de la intersubjetividad tan importantes como el sentimiento o la ética. Es más, ni la percepción, en Merleau-Ponty es una dimensión ajena al sentimiento, ni el Ser es pura presencia o aspiración narcisista; el otro es tan importante, para Merleau-Ponty, como el propio yo.

Levinas cree que los fenomenólogos priorizan la conciencia y, por consiguiente, entienden la relación intesubjetiva como una simple relación de conocimiento mutuo ${ }^{24}$. Él opina que el amor es más importante, ya que explica la

23. LEVNAS, E. (1945). Le tempset l'autre. Totalité et infini (1961).

24. LEVINAS, E. (1990. Intersubjectivity. Notes of Merleau-Evanston: Northwestern Univ. Press, p. 58 . 
relación interpersonal y preserva la diferencia. Yo diría que el amor es sólo una de las múltiples dimensiones de la intersubjetividad y que, aunque efectivamente reconozcamos su importancia, no es precisamente la relación más extendida entre todos los hombres. Además, creemos que sería necesario describir más detalladamente en qué consiste dicha relación. En una primera aproximación, podríamos decir, por ejemplo, que la relación amorosa puede efectivamente salvaguardar las diferencias yo-otro, pero también puede anularlas si se trata de un enamoramiento narcisista, egoista, etc. Si hiciéramos un análisis de las relaciones amorosas fácticas descubriríamos que Cupido no dispara sus flechas al azar, sino que parece conocer muy bien sus objetivos, es decir, las coincidencias culturales, espaciales, temporales, sociales, etc. entre los enamorados son mayores que las diferencias. Levinas piensa que no se puede hablar de un otro en abstracto, porque cada otro es único y su unicidad no puede ser representada o conocida por una ciencia de la generalidad, tampoco puede ser apresentada (la apresentación es el resorte último de una representación deficiente). Levinas propone la aproximación responsable, la obligación hacia los otros y el amor ${ }^{25}$.

C. Lefort acusa, a su vez, a Merleau-Ponty de olvidar, en sus análisis del fenómeno intersubjetivo, la explicación psicológico-genética y, en concreto, la percepción infantil ${ }^{26}$. Para el niño, el otro no es originariamente un alter ego; la mirada del otro abre un mundo para él, y en ese mundo no hay distinción entre el cuerpo propio y el cuerpo materno. Según Lefort, MerleatuPonty obvia la función del tercero, el que da los nombres, en el desarrollo infantil. El niño mismo es nombrado desde su nacimiento, se le impone una ley exterior.

Lefort parece concebir la reversibilidad como una relación entre dos términos (el interior y el exterior); en su opinión, la otredad no encaja en ella, porque requiere un término mediador, un tercero. Así se lo demuestra la experiencia infantil en la que no hay diferencia entre el dentro y el fuera y, por tanto, no se explica en la ontología de la carne sugerida por Merleau-Ponty.

Aunque no fue su objetivo prioritario, la obra de Merleau-Ponty es rica en estudios sobre la psicología infantil que hacen referencia a la intersubjetividad (Piénsese, por ejemplo, en Las relaciones con el otro niño). Además, no hay por qué presuponer, como hace Lefort, que el modelo de encuentro verdadero con el otro haya de ser el niño. Para concebir adecuadamente la alteridad, es necesario incluir la identidad y la diferencia o la inmanencia y la transcendencia, porque el otro ha de ser un orro genuino $y$, a la vez, un sujeto como yo. De este modo, persiste la ambiguiedad: el mundo del otro y el mío son idénticos y diferentes; el conocimiento del mundo intersubjetivo me habla de mi contingencia: el otro es el que me sobrepasa y así me afirma en el ser al mismo tiempo que en la angustia.

25. Ibídem, p. 66.

26. LFForT, C., "Flesh and Otherness", en Johnson, G.A.; Simitr, M.B., op. cit., p. 9. 
Lefort asegura que Merleau-Ponty no logra el error de Husserl: el cuerpo realiza la función transcendental de constitución que Husserl atribuía al ego transcendental, es decir, se proyecta en el mundo y atribuye diferencia y otredad a las cosas. El resultado es idéntico: una ontología que niega la transcendencia de las cosas y que, por lo tanto, es incapaz de explicar la alteridad. Pero Lefort no comprende que Merleau-Ponty se interesa por la alteridad verdadera y ésta no es la de los objetos, sino la de los otros sujetos. Además, no es cierto que niegue la transcendencia de las cosas; el carácter intencional de la conciencia fenomenológica lo prohibe. En nuestra opinión, el problema surge porque la carne no puede ser comprendida en una ontología realista, pero rechazar el realismo no equivale sin más a caer en el idealismo. Precisamente, toda la filosofía merleau-pontyana se niega a reducir la realidad a una u otra visión del mundo.

Merleau-Ponty afirma que somos en el mundo con los otros. Tanto las cosas como los hombres son transcendentes, pero sólo tengo información sobre ellos a través de mi percepción. La dialéctica circular de la inmanencia en la transcendencia define, pues, la teoría merleau-pontyana de la intersubjetividad; una dialéctica ambigua, quizás, pero adecuada para dar cuenta de nuestra realidad interpersonal.

\section{La relación entre filosofía y sociología}

La fenomenología merleau-pontyana consigue, a nuesto modo de ver, dar cuenta de esa realidad y por eso constituye una contribución imprescindible para la interpretación crítica del fenómeno sociológico. Es más, pensamos que la sociología es posible sólo si los fenómenos científicos se reinterpretan desde el plano de la historia y se introducen explicítamente en ellos categorías tan imprescindibles como valor, fin, racionalidad, etc.

La perspectiva humanístico-existencialista se integra en Merleau-Ponty con la perspectiva sociológico-estructuralista. Sin embargo, no hipostasia la estructurá ésta es tan sólo un esquema, un instrumento de lectura de la naturaleza social del sujeto. Lo social, para nuestro filsófo, es la intersubjetividad, la comunidad simultánea y sucesiva de la conciencia. La sociabilidad define nuestra esencia como nudo de relaciones. Estas son sumamente variables como nuestra propia existencia social, la cual se funda en nuestra existencia corporal. La sociabilidad realiza la esencia del hombre en el mundo. Una vez más, observamos el inmanetismo radical de Merleau-Ponty. La sociabilidad es elaboración colectiva de objetos culturales, intencionalidad práctica que caracteriza el comportamiento humano.

Según nuestro filósofo la investigación sociológica no puede desvincularse de la experiencia que tenemos como sujetos sociales; es decir, no podemos ser espectadores desinteresados. La sociología será, entonces, una ciencia esencialmente dialéctica, porque su objeto es la sociedad que está llena de contradicciones, de tensiones y cambios. El mundo social es otra de las múltiples dimensiones de nuestra existencia y no requiere un sujeto constituyente por- 
que nunca está plenamente acabado, sino que se va haciendo. Los roles de los otros son complementarios de los míos (por ejemplo, masculinidad implica feminidad, etc.). La autonomía solitaria es imposible, ya que ser autónomo no es otra cosa que asumir el propio comportamiento ante los otros, dar testimonio de sí.

Estamos viendo, y de hecho así lo afirmaba Merleau-Ponty, que la fenomenología puede prestar una inestimable ayuda a la sociología, y a la inversa. Después de todo, "todo sociólogo hace filosofía cuando no se limita a anotar hechos, sino que intenta comprenderlos para interpretarlos» ${ }^{27}$. La filosofía suministra a la sociología (y a la ciencia, en general) una experiencia global para que no pierda de vista sus verdaderos objetivos. A su vez, la filosofía no puede renunciar a juzgar el presente si no quiere perder su sentido. La filosofía y la sociología no se definen por unos campos de estudio que les sean propios; únicamente hablan del mundo, de los hombres y de sus obras. La sociología comprensiva necesita, pues, filosofia y el fundamento de toda comprension es para Merleau-Ponty lo social originario.

Para Merleau-Ponty, lo social no es un objeto, sino nuestra situación vivida en un presente vivido, por cuya mediación también el pasado histórico se hace accesible para mí. Lo social se me aparece siempre como una variación de mi vida particular en la cual participo y en términos de la cual mi semejante es siempre otro Yo, un alter ego. La socialidad es un modo de proyectarse y de ser-en-el-mundo irreductible a las situaciones naturales. Por el solo hecho de que existimos estamos en contacto con otros. Esta situación social en la que vivimos es fruto de una dialéctica entre situación circundante y conciencia.

Incluso nuestras relaciones con la naturaleza están ligadas a nuestras relaciones con los otros y a la inversa. Puesto que Merleau-Ponty concibe el yo como comportamiento, la intersubjetividad estará basada, en su opinión, en la continua comunicación con el otro: ésta tiene lugar porque estamos en el mismo mundo, porque percibimos y coexistimos con él.

Merleau-Ponty ha subrayado los inconvenientes de la separación —operada por el positivismo- entre las ciencias sociales y la filosofía. Este filósofo defendió siempre la necesidad de restablecer la conexión entre conocer y ser, entre la reflexión y el mundo prerreflexivo del que proviene. Nunca hizo de la sociedad una mera colección de entidades monádicas, sino una estructura fundamental de la experiencia, un campo permanente para cualquier acción, para cualquier subjetividad, del mismo modo que el mundo es el horizonte permanente de toda percepción. A la sociedad así entendida, como un todo, Merleau-Ponty la llamó estructura, porque conecta los significados sociales que operan en diferentes niveles y articula los significados actuales con los significados posibles y con los fenómenos sociales.

Para concluir, digamos que la intersubjetividad que Merleau-Ponty acepta es, ante todo, intercorporeidad. Esto hace que el otro de Merleau-Ponty sea expli- 
cito y abierto, frente al yo solitario de Sartre. La lengua común que hablamos es, para Merleatı-Ponty, semejante a la corporeidad anónima que compartimos con los otros. Pero, además, concibe la intersubjetividad como una estructura dialéctica: la autorrealización del hombre se basa en el carácter intersubjetivo de nuestra existencia y comunicación con los otros, pero, a la vez, la verdadera intersubjetividad supone la conciencia clara de la propia y distinta subjetividad. En realidad, los hombres somos siempre uno para el otro, colaboradores en una reciprocidad perfecta, coexistencias en el seno de un mismo mundo compartido.

Merleau-Ponty intentó encontrar la Einfühlung del yo en el otro y se dio cuenta de que la relación yo-otro sólo se da entre roles complementarios. De este modo, rechazó toda posible constitución del otro ante ego y reconoció que, para ser nosotros mismos, necesitamos aproximarnos a los demás y reconocerlos como otros sujetos. 